\title{
HIJOS DE LA REVOLUCIÓN: LA ÓPERA PADILLA \\ O EL ASEDIO DE MEDINA Y LA CULTURA POLÍTICA \\ DEL LIBERALISMO PROGRESISTA EN MADRID \\ ENTRE 1842 Y 1846
}

\begin{abstract}
Children of the Revolution: The opera Padilla or the Siege of Medina and the political culture of progressive liberalism between 1842 and 1846 in Madrid
\end{abstract}

\author{
TERESA CASCUDO GARCÍA-VILLARACO \\ Universidad de La Rioja \\ teresa.cascudo@unirioja.es
}

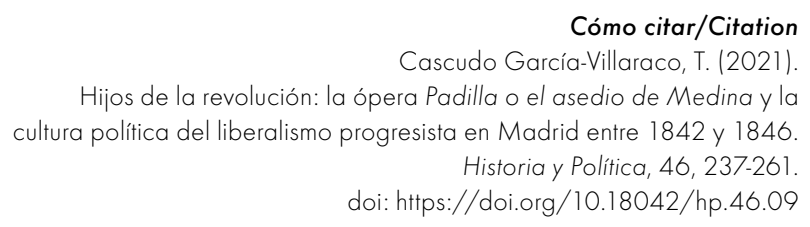

(Recepción: 24/02/2020; evaluación: 19/04/2020; aceptación: 19/09/2020; publicación: 30/11/2021)

Resumen

El liberalismo progresista se articuló a mediados del siglo xix en España como una corriente ideológica que, por diversos motivos, ha permanecido oculta bajo el manto de otros discursos que han hegemonizado el relato de las culturas políticas. Gracias a estudios relativamente recientes, tenemos hoy en día un conocimiento más detallado de dicho movimiento - tanto en lo que concierne a las diferentes facciones que lo conformaron como en lo referente a las figuras públicas que se adhirieron a

1 El presente artículo es resultado de un plan de investigación financiado en 2019 por el Instituto de Estudios Riojanos, en cuya biblioteca se custodia material musical de la ópera Padilla o el asedio de Medina. 
él一, así como de los escritores que conciliaron creación artística y negocio con la difusión de sus principios políticos. Partiendo de esas investigaciones previas, este artículo propone una lectura de la ópera Padilla o el asedio de Medina, estrenada en Madrid en 1845, que tiene en cuenta la cultura política de la que formaron parte sus autores, el escritor Gregorio Romero Larrañaga y el compositor Joaquín Espín y Guillén, y los espacios de sociabilidad que frecuentaron en un momento histórico en el que se reactivó el uso de determinados símbolos del progresismo con una función comunicativa. Este artículo demuestra, en última instancia, que Padilla o el asedio de Medina, inspirada en las revueltas comuneras, además de ser un hito en el desarrollo del teatro lírico nacional español, fue el resultado de una cooperación artística en gran medida condicionada por afinidades e intencionalidad políticas.

\title{
Palabras clave
}

Cultura política; liberalismo progresista; ópera nacional; prensa del siglo XIx.

\begin{abstract}
Progressive liberalism was articulated in the mid-nineteenth century in Spain as an ideological trend. For several reasons, it has remained hidden beneath other discourses which have hegemonized the history of political cultures. However, thanks to the increasing research on progressive liberalism, we have today a more detailed knowledge of this movement, both regarding the different factions that formed it and the public figures that adhered to it, especially the writers that combined art and business with the diffusion of the political principles that they shared. Based on these previous investigations, this article proposes a reading of the opera Padilla or the siege of Medina, premiered in Madrid in 1845, which considers spaces of sociability linked to music and the political culture shared by its authors: the writer Gregorio Romero Larrañaga and the composer Joaquín Espín y Guillen. Thus, this opera is contextualized in the delicate historical moment that led to the period known as the Moderate Decade, which favoured the use of specific symbols of progressivism - among others, the Comunero movement - with a clear communicative function. This contextualization is carried out in this article by using the press as the primary source and by placing the opera and its authors within the framework of three types of networks: social, media and intertextual ones. Ultimately, it shows that Padilla or the siege of Medina, a milestone in the development of Spanish national lyric theatre, was the result of artistic cooperation largely conditioned by political affinities.
\end{abstract}

\section{Keywords}

Political culture; progressive liberalism; national opera; nineteenth-century press. 
I. INTRODUCCIÓN. II. UNA RED SOCIAL DE ARTISTAS PROGRESISTAS COHESIONADA POR LA LITERATURA Y LA MÚSICA. III. DE LA ACTIVIDAD MUSICAL DE ESPÍN Y GUILLÉN COMO ACTIVISMO PROGRESISTA. IV. PADILLA O EL ASEDIO DE MEDINA EN RED MEDIÁTICA E INTERTEXTUAL. V. CONCLUSIÓN. BIBLIOGRAFía.

\section{INTRODUCCIÓN}

El compositor Joaquín Espín y Guillén (1812-1881) fue uno de los artífices del desarrollo del teatro lírico nacional español ${ }^{2}$, tanto en la vertiente doctrinal, por así decirlo, como en su vertiente práctica. En lo que respecta a la primera, es innegable que desde las páginas de la revista que fundó en 1842, La Iberia Musical ${ }^{3}$, contribuyó a consolidar en la esfera pública la idea de que la nación española debía tener una ópera propia. En lo que se refiere a la segunda, el estreno madrileño en julio de 1845 de cinco números de Padilla o el asedio de Medina, partitura de su autoría cuyo libreto se debe a Gregorio Romero de Larrañaga, se suele mencionar como un hito de la historia de la ópera en España, aunque a pesar de la importancia que se le atribuye nunca se ha planteado hasta qué punto el proyecto de ópera nacional española, tal como fue puesto en marcha por Espín y Guillén, estuvo vinculado a factores contextuales de orden productivo, pero también, y sobre todo, de orden intelectual, ideológico y político ${ }^{4}$. Hubiera resultado cuanto menos sorprendente que se hubiera escrito algo concluyente sobre el asunto, tomando en consideración que la ópera nunca llegó a representarse por entero y que durante décadas se ha dado por extraviada. La localización en 2017 de la partitura general de las escenas cantadas en el mencionado

2 La expresión «desarrollo del teatro-lírico-nacional», en cursiva, fue usada por el propio Espín y Guillén, como veremos más adelante.

3 La revista pasó a llamarse en 1843 La Iberia Musical y Literaria. En 1846 volvió a salir de forma irregular bajo su título original. Una descripción de la fuente en Fuentes Garzón (2018).

4 En lo que respecta a la biografía de Espín y Guillén, se puede consultar Rodríguez Lozano (2006). La génesis de la obra se debe contextualizar en el proceso más amplio de «nacionalización de la cultura» estudiado por Álvarez Junco (2001: 187-302). 
estreno madrileño, así como del libreto completo, cambió de forma sustancial esta situación'.

El descubrimiento de esta nueva fuente musical justifica, sin duda, su interés en la perspectiva de la musicología. No obstante, los objetivos de este artículo van más allá de los límites habituales en esa disciplina. Pretende, por un lado, ser una contribución a una línea de investigación que sonoriza la historia y que empieza a ganar cierta relevancia ${ }^{6}$. Por otro, persigue reforzar la introducción en la investigación musicológica del concepto de cultura política, puesto que el significado del estreno de Padilla o el asedio de Medina, que hasta ahora solo se ha planteado como un episodio dentro del problema más amplio de la creación de una ópera nacional en España ${ }^{7}$, empieza a resultar plenamente comprensible cuando se pone en un contexto diferente que, como acabo de apuntar, es de carácter político e histórico. Es, además, transnacional, como se puede comprobar a través de la lectura del trabajo de Carlotta Sorba acerca de la transferencia de las convenciones del melodrama francés al ámbito del teatro musical ocurrido en la época del Risorgimento, durante el cual, al igual que en la España de la primera mitad del siglo xix, mutatis mutandis estaban en juego la cuestión de la unidad nacional y del antagonismo entre liberales y absolutistas. Tal como analiza Sorba para el caso italiano, de lo que se trató fue de la instrumentalización de una modalidad de narración que combinaba el sentimentalismo y la simplificación moralista, pero que, sobre todo, pretendía intervenir en la realidad contemporánea ${ }^{8}$. En lo que respecta a Espańa, la ópera italiana proporcionó un modelo a los compositores, aunque en su doble dimensión de espectáculo y modo de producción también puso en evidencia las dificultades que los autores locales tenían para acceder a los teatros especializados en el género?.

5 El núcleo del que forman parte estas fuentes musicales se conserva en el archivo personal de Manuel Salvador Carreras, custodiado por el Instituto de Estudios Riojanos desde finales de 2017 gracias a un depósito cedido por sus herederos.

6 Véase, por ejemplo, Andreu Miralles (2019). En el ámbito de la musicología mencionaré como referencia los trabajos de Fulcher (1987) y Pasler (2009) entre otros.

7 Casares Rodicio (2019: 144-149).

8 Sorba (2015). Véase, además, Sorba (2011), donde para el caso italiano llega a la siguiente conclusión: «It is quite apparent that as the revolutionary triennium 18461849 approached, the distinction between text and subtext, between the stage and reality, became more and more blurred in a framework of strong convergence between life and the theater» (2011: 447).

9 La recepción de la ópera italiana en España es un tópico historiográfico bastante visitado por la musicología. A una aproximación esencialista, de la que Emilio Casares Rodicio (1998) puede ser considerado la referencia por antonomasia, le ha sucedido 
Uno de los trazos principales del nuevo orden social propio del liberalismo, tal como se estableció en la España del siglo xix, fue la tensión entre un sector progresista que, en conexión con las clases populares, impulsó la revolución y un sector moderado que tuvo en sus manos los medios para la construcción del Estado ${ }^{10}$. El progresismo en particular es una corriente ideológica que, por diversos motivos, ha permanecido oculta bajo el manto de otros discursos que han hegemonizado, en lo que concierne a la España del siglo xIX, el relato de las culturas políticas y que solo ha empezado a ser estudiada con detalle recientemente ${ }^{11}$. No se me escapa que esta situación sea, en gran parte, la explicación de que esta relación entre discurso progresista y construcción de una ópera nacional no se haya tenido en cuenta hasta ahora.

En este artículo intentaré fijar primeramente el contexto del que los autores de Padilla o el asedio de Medina, Romero Larrañaga y Espín y Guillén, formaron parte durante la Regencia de Espartero y los primeros meses de la Década Moderada ${ }^{12}$. Como acertadamente ha sintetizado Carmen de la Guarda Herrero con respecto al caso español, la correlación entre espacios de sociabilidad creados por la sociedad civil y la generación de corrientes de opinión es consustancial al liberalismo ${ }^{13}$. A los espacios de sociabilidad formal e informal que enumera en su artículo, añado en este estudio varios en los que la música tuvo una notable preponderancia, algunos de los cuales - especialmente la redacción del periódico La Iberia Musical y Literaria - nunca habían sido abordados desde ese punto de vista. De hecho, y a falta de otras fuentes primarias disponibles, utilizaré como fuente principal la prensa. Así, mostraré la red, al mismo tiempo social e intertextual, de la que Padilla o el asedio de Medina y sus autores formaron parte. En lo que se refiere a su vertiente social, me centraré en las interrelaciones forjadas en un entorno de sociabilidad concreto, el artístico, considerando como aglutinadores por un lado a ambos

recientemente otra más estructural y preocupada por establecer y destacar los complejos vínculos de la composición musical en España con su contexto cultural y social, representada por Juan José Carreras (2018). Esta contraposición se aplica igualmente a la cuestión de la ópera nacional. Así, los postulados esencialistas de Casares se reiteran en publicaciones más recientes (2017). Desde la perspectiva de la historia general, contamos con la reciente síntesis de Xavier Andreu Miralles (2019).

10 Sigo en este punto a Millán y Romero (2008).

11 A este propósito, véase Burdiel (2000); Romeo (2003), y Sierra (2010).

12 Un ejemplo del alcance de la propaganda progresista en los años anteriores, lo ha estudiado Pérez Núñez (2016).

13 Guardia Herrero (2014). En el ámbito de la musicología y con respecto a la relación entre espacios de sociabilidad de las élites y política, véanse especialmente los trabajos de Carolina Queipo (2015, 2019a, 2019b). 
personajes, y por otro la política ${ }^{14}$ y la música. Abordaré adicionalmente en detalle las colaboraciones periodísticas de Espín. Analizaré su proyecto de construcción de una ópera española desde la perspectiva que nos abren las redes reconstruidas en el primer epígrafe. Finalmente, en la tercera sección de este estudio me centraré en las redes intertextuales que hacen relevante desde el punto de vista político la ópera Padilla o el Asedio de Medina, para así reforzar mi hipótesis de su conexión con el activismo progresista de la década de los cuarenta del siglo xIX.

\section{UNA RED SOCIAL DE ARTISTAS PROGRESISTAS COHESIONADA POR LA LITERATURA Y LA MÚSICA}

La libertad para Juan Martínez Villergas, uno de los autores que podemos situar en este entorno político, era no solo una palabra de orden, sino la «musa del porvenir» que inspiraba a los escritores progresistas y, en particular, a los democráticos ${ }^{15}$. Villergas escribió esto en un estudio dedicado al dramaturgo Eduardo Asquerino. Tanto Villergas como Asquerino, así como Romero de Larrañaga, han sido identificados en la esfera demorrepublicana por Florence Peyrou, quien, sin embargo, no menciona en ningún momento a Espín y Guillén. Lo relevante, sin embargo, no es esta ausencia, sino que la demostrada filiación política de los primeros — con los que Espín mantuvo, como veremos, estrechos lazos - invita a poner bajo una nueva perspectiva la filiación política del compositor a mediados de la década de los cuarenta del siglo xix. En esa constelación de relaciones personales, además de los ya mencionados —entre los que incluimos al compositor y al libretista, juntamente con Eduardo Asquerino y Villergas - traeré a colación otros nombres, tales como los de Eusebio Asquerino, Ramón Satorres, Ramón de Valladares y Saavedra, Miguel Agustín Príncipe y Vidaud, Blas María Araque y Wenceslao Ayguals de Izco. Mencionaré además a otras figuras públicas del momento, tales como los dramaturgos Juan Eugenio Hartzenbusch y Tomas Rodriguez Rubí, quienes participaron en iniciativas comunes, o al editor Francisco de Paula Mellado y el banquero José de Salamanca, quienes apoyaron en momentos puntuales el trabajo musical de Espín.

\footnotetext{
14 Me baso en Peyrou (2008). Gracias a esta investigación conocemos al pormenor las vicisitudes del movimiento demorrepublicano durante el reinado de Isabel II, así que constituye una de las referencias principales del presente artículo.

15 Martínez Villergas (1854: 280).
} 
La primera noticia documentada en la prensa de una audición de algún fragmento de Padilla o el asedio de Medina data de enero de $1844^{16}$. Se deduce de ahí, como es evidente, que Romero de Larrañaga y Espín debieron de haber trabajado en el libreto desde el año anterior. Estos meses coincidieron con una fase política cambiante, durante la cual el progresismo vio bastante limitada su capacidad de intervención ${ }^{17}$. En enero de 1844 , el sector moderado se hizo con las Cortes. La facción menos liberal de este sector afianzó su poder a lo largo de un proceso consolidado en mayo del mismo año, cuando la reina encomendó al general Ramón María Narváez el nombramiento del Gobierno. Durante los meses de febrero y marzo, las revueltas instigadas por el sector progresista se habían sucedido. Así, según señala Florencia Peyrou, en 1845 había al menos seiscientas personas detenidas como consecuencia de los disturbios ${ }^{18}$. El ambiente revolucionario se mantuvo cerca de dos años. Pocas semanas después del nombramiento del general Narváez, el 4 de julio de 1844, se publicó un decreto de disolución de las Cortes y convocatoria de elecciones, previstas para septiembre, que fue duramente criticado en los medios progresistas. Interesa notar que buena parte de dichas críticas incidieron en la cuestión de la soberanía nacional ante la deriva hacia el doctrinarismo que representaban los moderados: según periódicos como El Clamor Público o el Eco del Comercio, el fundamento implícito del decreto era que dicha soberanía ya no residía en la nación, sino en la Corona, en la medida en la que esta asumía la iniciativa de la reforma constitucional ${ }^{19}$. La opción tomada por el sector progresista ante las elecciones de 1844 fue la abstenerse. Esto llevó consigo la desaparición de la opción que representaba en las Cortes hasta las elecciones de diciembre de 1846.

En ese contexto se entiende que a partir de 1843, tal como también señala Florencia Peyrou, se consolidase "una tendencia política democrática» coincidente con la radicalización de sectores que hasta entonces «se movían en la órbita de un liberalismo exaltado o radical y de un progresismo de izquierdas ${ }^{20}$. Desde este sector se trabajó de forma consciente en la labor popularizadora de las ideas que defendía, una labor realizada por un número considerable de escritores y periodistas y que conoció un momento de especial intensidad

\footnotetext{
16 Teodoro Guerrero [y Pallarés], «Concierto de La Iberia Musical y Literaria», La Iberia Musical y Literaria, 3 (7), 1-2-1844, 35-6.

17 Sobre las vicisitudes del progresismo en España, además del mencionado libro de Peyrou, véase como resumen Vilches (2001: 27-55 especialmente).

18 Peyrou (2008: 165).

19 Villarroya (1977).

20 Peyrou (2008: 169).
} 
en estos momentos. En realidad, esta actividad de adoctrinamiento y proselitismo era una característica propia del sector progresista, que según se señaló incluso en la prensa moderaba cuidaba «interesar a todas las clases [...] al honrado labrador, aun cuando no sea de colosal fortuna, al comerciante, al fabricante, al artista, al médico y a otras muchas clases respetables ${ }^{21}$. Si bien es cierto que, con respecto a esta época, en muchas ocasiones resulta difícil decidir qué etiqueta política concreta aplicar, lo que sí está demostrado es que este sector progresista, en el que se encontraban progresistas más avanzados, demócratas y republicanos, además de masones, y que mantenía igualmente canales de comunicación y colaboración con un sector centrista a cuyos miembros, en la época, se les conocía como "puritanos»" ${ }^{22}$, consiguió articular medios diversos para difundir sus ideas no solo entre lo que los moderados consideraban ser «las clases respetables», sino también entre las clases populares. Es lógico que este proyecto, además de la literatura y el teatro declamado, contemplase igualmente el género dramático-musical, el cual, como Espín no se cansó de señalar en las páginas de La Iberia Musical y Literaria, hegemonizaba el gusto musical contemporáneo.

En primer lugar, los autores mencionados colaboraron en empresas de carácter periodístico. Así, en 1842 las páginas de La Iberia Musical reunieron a Espín con Romero Larrañaga y Príncipe, un equipo al que en su segunda serie (La Iberia Musical y Literaria) se sumó Martínez Villergas, quien parece que asumió un papel relevante como editor de la parte literaria ${ }^{23}$. En 1843 la prensa también menciona a Príncipe, Romero de Larrańaga y Martínez Villergas como redactores en el anuncio de la revista literaria y musical $E l$ Genio, en la que también se contaba con Espín como colaborador para la parte musical ${ }^{24}$. Que la red era, por supuesto, más amplia y, además de lo político, incluía relaciones de carácter comercial, lo podemos comprobar en las páginas de la revista satírica La Risa, donde algunos de ellos llegaron a figurar como parte de un grupo a mediados de $1844^{25}$. Fueron entonces reproducidas

21 Citado por Villarroya (1977: 79).

22 Véase Prieto Benavent (2000).

23 Aparece, por ejemplo, como cofirmante juntamente con Espín y Guillén de un comunicado publicado en la Revista de Teatros. Véase "Comunicado», Revista de teatros. Diario pintoresco de literatura, 76, 15-3-1844, 2.

24 El anuncio se publicó en varios periódicos, por ejemplo: [Sin firma], «Publicaciones periódicas. El Genio. Periódico de literatura y música», El nuevo avisador. Diario de anuncios oficiales y noticias locales, 3-1-1843, 2.

25 Wenceslao Ayguals de Izco, "A mi amigo don Juan Martínez Villergas», La Risa. Enciclopedia de extravagancias, 56, 5-5-1844, 42-45. 
caricaturas gráficas de Príncipe, Rubí, Espín y Asquerino, así como de Hartzenbusch: los escritores mencionados tenían en común la participación en la Sociedad Literaria de los hermanos Ayguals de $\mathrm{Izco}^{26}$. Más relevante resultará saber que en 1844 La Iberia Musical y Literaria pasó a ser gestionada por la empresa Uzal y Aguirre, uno de cuyos administradores era el republicano Manuel García Uzal ${ }^{27}$. Antes de eso, en 1842, la revista se había impreso en un establecimiento tipográfico de Francisco de Paula Mellado y Orejuela, quien era frecuentador del Liceo Literario y había colaborado previamente con Romero Larrańaga en iniciativas editoriales ${ }^{28}$.

Idearon, en segundo lugar, otros proyectos periodísticos y artísticos caracterizados por la colaboración de literatos y músicos. Durante el verano de 1840, por ejemplo, fundaron un Museo Lírico, Literario y Artístico, alabado por Fray Gerundio como muestra de lo que eran capaces de hacer sin ningún apoyo estatal los jóvenes intelectuales de la época ${ }^{29}$. Espín era presidente de la sección de música y fue nombrado responsable de la cátedra de Canto en $1842^{30}$. Fue ese ańo cuando el museo inauguró su actividad, muy efímera ${ }^{31}$. Antes de esto, todos habían coincidido en otras organizaciones de mecenazgo colectivo, tales como el Liceo Artístico y Literario y el Instituto Español, organizaciones con las que Espín colaboró en calidad de músico ${ }^{32}$. A algunos de ellos los encontramos participando en las sesiones poético-musicales organizadas en 1844 por La Iberia Musical y Literaria en los salones del Instituto Español. En este punto vale la pena señalar que, tal como se veía desde la

26 La Sociedad Literaria de Ayguals de Izco ha sido estudiada en la perspectiva comercial por Baulo (2005).

27 Según Pérez Roldán (1999), la tipografía y establecimiento de libros estaba situada en el número 16 de la calle Jardines, en Madrid. García Uzal colaboró con Ayguals de Izco y editó a Eduardo Asquerino.

28 Sobre la actividad de este editor, véase Martínez Martín (2018).

29 Fray Gerundio, capillada 275, 18-8-1840, 219. Este periódico satírico era editado por Mellado y redactado por Modesto Lafuente, entonces público militante progresista. En lo que respecta a la orientación política y función de este periódico en el entramado empresarial de Mellado, véase Martínez Martín (2018: 64-71).

30 [Sin firma], «Crónica nacional», La Iberia musical, 13, 27-3-1842, 3.

31 [Sin firma], «Museo lírico, literario y artístico. Días y horas de sus cátedras», El Eco del Comercio, 19-5-1842, p. 4. En 1844, se daba por extinguido, según se menciona en la breve biografía de Agustín Príncipe, uno de sus fundadores, contenida en Hidalgo (1844: 309).

32 Las sociedades musicales han constituido objeto de estudio en el ámbito de la musicología. En lo que se refiere al período isabelino, véase Díez Huerga (2004) y Queipo (2019a). 
revista, la decadencia de la actividad artística del Liceo Literario de Madrid justificó la organización de otro foco de actividad literaria y musical, de la que se erigió como la principal «regeneradora»"

A modo de ilustración, me detendré en los conciertos que organizaron durante los primeros meses de 1844. En enero, dentro del mismo programa en el que, como he indicado más arriba, se escuchó por primera vez un fragmento de la ópera Padilla o el asedio de Medina, participaron los ya mencionados Romero Larrańaga y Eduardo Asquerino, además de Teodoro Guerrero, otro autor que formaba parte de la ya mencionada Sociedad Literaria ${ }^{34}$. En el segundo concierto de la serie colaboraron Rubí, Romero de Larrańaga y Ayguals de Izco $^{35}$. En el siguiente, para el cual se anunció la ejecución de parte de la Tercera Sinfonía, conocida como Heroica, de Ludwig van Beethoven, y se cantó el Stabat Mater de Rossini, colaboraron en la parte poética uno de los hermanos Asquerino y, de nuevo, Romero Larrañaga y Rubíi ${ }^{36}$. Resulta significativo que para el cuarto concierto, organizado en abril, la revista intentase contar con la presencia de la reina madre ${ }^{37}$. La tentativa fue infructuosa, pero no por ello deja de ser indicativa de la utilidad política de este tipo de reuniones artísticas. Otro ejemplo de estas colaboraciones coincide con una ocasión tan señalada como lo fue la visita de Franz Liszt a Madrid ${ }^{38}$. Espín y Guillén, en su calidad de director de La Iberia Musical y Literaria, organizó en el Instituto Español una sesión literario-musical en la que participaron, además del célebre músico, Villergas y Larrañaga declamando versos de su autoría ${ }^{39}$. En uno de los banquetes organizados en honor del pianista y compositor de origen húngaro, Larrañaga fue el encargado de hacer el brindis en español e italiano ${ }^{40}$.

33 Mariano Soriano Fuertes, "Concierto de La Iberia Musical y Literaria celebrado el día 29 del pasado mes de febrero en el elegante y magnífico salón del Instituto Español», La Iberia Musical y Literaria, 3 (18), 5-3-1844, p. 69. En cuanto a la valoración que hacía Espín y Guillén del Liceo en este momento, véase «Liceo de Madrid. Memoria de la Junta Delegada», La Iberia Musical y Literaria, 3 (12), 11-2-1844, p. 45.

34 En ese concierto se cantó, con acompañamiento de gran orquesta, el coro de mujeres que constituye el tercer número del primer acto.

35 Mariano Soriano Fuertes, «Concierto de la Iberia Musical y Literaria...».

36 [Sin firma]: "Corresponsal. Madrid, 25 de marzo", El Corresponsal. Diario de la tarde, 25-3-1844, p. 4.

37 [Sin firma]: "Cuarto concierto de la Iberia Musical y Literaria», La Iberia Musicaly Literaria, 3 (2), 21-4-1844, 126.

38 Sobre la dimensión mediática de la gira española de Liszt, véase Simón Montiel (2015).

39 «Crónica interior», El Imparcial, 20-11-1844, 2.

40 [Sin firma]: «Banquete a Liszt», El Heraldo, 7-11-1844, p. 4. La proyección internacional de la carrera de Liszt es sobradamente conocida, pero quizá no lo sea tanto su 
En tercer lugar, también están documentadas colaboraciones artísticas, concretadas en las canciones puestas en música por Espín y Guillén a partir de poesías de varios de los autores mencionados. Por ejemplo, ya en 1842 escribió la música de tres canciones sobre poesía de Romero Larrañaga ${ }^{41}$ y otras dos sobre texto de Príncipe ${ }^{42}$. En 1844 también usó textos de Rubíi ${ }^{43}$ y, de nuevo, Príncipe ${ }^{44}$. Todavía en mayo de 1846 fue anunciada la canción «Las rosas de amor", sobre texto de Ayguals de Izco, que fue incluida en su popular novela María, la hija de un jornalero ${ }^{45}$. Además, a principios de 1845 Romero de Larrañaga, Villergas y Espín por un lado, juntamente con Eusebio y Eduardo Asquerino, Hartzenbusch y Rubí, en una reunión organizada en la casa del primero, se comprometieron a escribir piezas para una proyectada función en beneficio de los presos que se encontraban en la cárcel por motivos políticos. Este activismo se presentó como resultado de «ideas humanitarias» que no debían «rozarse para nada con la política» ${ }^{46}$. No obstante, la noticia se recogió en varios periódicos, incluyendo entre ellos a medios moderados que informaron a sus lectores utilizando los siguientes términos: "Algunos periódicos y literatos progresistas de esta capital han proyectado dar en uno de los teatros de esta corte una función escogida a beneficio de los presos por causas políticas ${ }^{47}$. El acuerdo era que Hartzenbusch y Rubí y los hermanos Asquerino escribieran dos comedias y que Villergas y Romero Larrañaga escribiesen

vinculación en estos años con el reformismo social sansimoniano. Fue partidario de la utilización de la composición musical como forma de activismo social. Véase, a este respecto, Locke (1986).

41 «La aldeana», «La africana» $\mathrm{y}$ "El adiós de un artista»: las dos primeras se editaron por La Iberia Musical y Literaria y la tercera, en el boletín de noticias de Fray Gerundio.

42 «La caprichosa» y el himno del Museo Lírico, Literario y Artístico. Sobre la relación de Príncipe con la música, véase Gutiérrez (2010).

43 «El serrano», cantada en el primero de los conciertos de 1844 y después comercializada.

44 Una canción española que la soprano Annunziata Tirelli cantó, en febrero de 1845, al final del tercer acto de Don Pasquale, la ópera de Donizetti.

45 Véase, a propósito de esta novela, Andreu Miralles (2017).

46 [Sin firma]: «Revista de teatros. Función a beneficio de los presos por toda clase de opiniones políticas", Revista de Teatros. Diario pintoresco de literatura, 215, 13-11845,2 . El editor Francisco de Paula Mellado y Orejuela le atribuye a Larrañaga dos libretos destinados a que Espín y Guillén les pusiera música en la biografía que redactó para el Diccionario Universal de Historia y Geografía (1850: 276). En cualquier caso, la partitura de la zarzuela no está actualmente localizada.

47 [Sin firma]: «Madrid. Gaceta de hoy», El Castellano, 15-1-1845, 3. 
el libreto para una zarzuela cuya música sería de la autoría de Espín y Guillén. En junio del mismo año, fueron finalmente representadas las piezas Una onza a terno seco y Haz bien sin mirar a quién, la primera de Hartzenbusch y Rubí, y la segunda de los hermanos Asquerino ${ }^{48}$. En abril se publicó que ya la zarzuela estaba terminada, pero que no había dinero para copiarla ${ }^{49}$. En mayo, La Iberia Musical y Literaria anunció que la zarzuela de Villergas, Larrañaga y Espín no se representaría «en beneficio de los presos por opciones políticas, a causa [...] de que algunos artistas líricos no se determinan a decir la parte recitada ${ }^{50}$ ¿Temerían represalias? El 6 de junio todavía se ignoraba si se montaría o no ${ }^{51}$, pero al final no se ejecutó "para evitar gastos mayores»". Pocos días después, en julio de 1845, José de Salamanca, que se situaba políticamente en un sector centrista vinculado al mismo tiempo con la oposición más liberal dentro del moderantismo y con la facción más moderada del progresismo ${ }^{53}$, le cedió a Espín y Guillén el Teatro del Circo, del que era empresario, para representar en beneficio del compositor el primer acto de Padilla ${ }^{54}$.

Finalmente, tras una ausencia de varias semanas durante las cuales Espín y Guillén se desplazó a Italia por motivos familiares, su nombre reapareció en la prensa unido al de algunos de los autores que he ido mencionando. Los ya conocidos Agustín Príncipe, Martínez Villergas, Ayguals de Izco, Satorres, Araque y Romero Larrañaga, juntamente con el propio Espín y Guillén, firmaron un comunicado en la prensa, publicado en febrero de $1846^{55}$. Lo enviaron en defensa de ciertas descalificaciones que se habían dirigido al improvisador italiano Pasquale Cataldi, quien además de sus cualidades artísticas exhibidas en reuniones privadas organizadas en las casas de Espín y Ayguals, compartía con los firmantes la misma orientación política progresista ${ }^{56}$.

48 [Sin firma]: «Gacetilla de la capital», El Heraldo, 10-6-1845, 3.

49 [Sin firma], Revista de Teatros. Diario pintoresco de literatura, 806, 16-4-1845, 2. Como he señalado más arriba, Florencia Peyrou cifra en seiscientod el número de presos.

50 El redactor exclamó seguidamente: «Vaya en gracia!». [Sin firma], «Álbum», La Iberia Musical y Literaria. Gaceta de Teatros, 4 (57), 8-5-1845, p. 148.

51 [Sin firma], «Crónica de Teatros», El Clamor Público, 6-6-1845, 4.

52 [Sin firma], "Filantropía y patriotismo», Eco del Comercio, 21-6-1845, 3. Se informaba en este número de los gastos y del beneficio final del espectáculo.

53 En 1845, el grupo de los puritanos rompió con Narváez. Según Prieto Benavent (2000: 252-254), la relación de Salamanca con ellos era anterior a esa fecha.

54 [Sin firma], «Gacetilla de la capital», El Heraldo, 10-6-1845, 3.

55 [Sin firma], «Comunicados». Eco del Comercio, 24-2-1846, 4.

56 Natali (2009). Sobre este tipo de poetas improvisadores y su relación con el patriotismo progresista, véase Scardicchio (2012). 


\section{DE LA ACTIVIDAD MUSICAL DE ESPÍN Y GUILLÉN COMO ACTIVISMO PROGRESISTA}

Espín y Guillén fue un prolífico crítico musical, por lo que la prensa documenta profusamente lo que denominaré su activismo en el ámbito de la música. Según lo interpreto, dicho activismo debe ser encuadrado en el contexto de las redes que he mostrado en la primera parte de este artículo. Sus escritos sobre ópera son muy numerosos, por lo que no procuraré hacer un resumen de los mismos, sino que, más bien, intentaré reconstruir, a veces a partir de comentarios marginales, la concepción del compositor acerca del proyecto de construcción de una ópera nacional española. En noviembre de 1842 Espín afirmaba en uno de sus primeros artículos de La Iberia Musical y Literaria que la política era «ajena» al arte de la música, mientras que, irónicamente, empezaba su texto aludiendo a la actualidad política del momento ${ }^{57}$. De hecho, esta alusión a la contemporaneidad es bastante recurrente en sus intervenciones periodísticas. Como señaló en una de sus críticas de 1843:

Los tiempos se suceden unos a otros con la rapidez del rayo, así como los mortales disfrutamos a cada paso sensaciones diversas, y gozamos más, cuanto más difieren entre sí los objetos que son la causa inmediata de estas sensaciones. Ayer corríamos agitados a entrar en el templo de Dios, sufriendo empellones y diversos azares, tan solo por escuchar las Siete palabras; hoy corremos en distinta dirección, con diverso fin, a escuchar en el Teatro Circo las sublimes partituras de Donizetti y Bellini. ;Lo que va de ayer a hoy. ${ }^{58}$.

Parece inevitable relacionar esta sensación de rapidez con la cambiante actualidad política contemporánea anteriormente descrita. Aunque, más allá de la mera sensación de cambio acuciante, el acceso de políticos progresistas a lugares de decisión tenía consecuencias concretas que también podían incidir

57 «No crean nuestros amables lectores que al decir Giuramento, vamos a recordar el que prestó en las cortes el regente del reino, ni los artículos de la constitución, ni nada que se roce con la política ni con los partidos; felizmente nuestro arte es extraño a los partidos y a la política, y nosotros quisiéramos que todos nuestros hermanos (los españoles) se peleasen por aprender, aunque fuese de memoria, una docena de canciones populares y no andarse buscando el bullo tan encarnizadamente como pueden hacerlo los cafres», Joaquín Espín y Guillén, "Il Giuramento. Beneficio de la seńora Basso-Borio", La Iberia Musical y Literaria, 1 (13), 27-11-1842, p. 100.

58 Joaquín Espín y Guillén, "Teatro del Circo. Marino Falliero. Norma», La Iberia Musical y Literaria, 2 (17), 23-4-1843, 129. 
en el ámbito de la composición musical. Vemos esta conexión en un rumor publicado en primicia en febrero de 1843, también en las páginas de La Iberia Musical y Literaria, según el cual el progresista Juan Álvarez Mendizábal, a la sazón recién nombrado y efímero alcalde de Madrid, proyectaba construir un teatro «destinado a la creación de la ópera nacional» en un convento ocupado por la Milicia Nacional. El redactor, muy probablemente el propio Espín, comenta: «Si viésemos que se lleva a cabo la idea, el que estas líneas suscribe compondría una operita nacional, se la dedicaría a D. Juan [Álvarez Mendizábal] y costearía todos los gastos. Entusiastas por las glorias artísticas de nuestra patria y por todo lo que huela a españolismo neto, arrojamos el guante al sr. Mendizábal, recójalo y veamos quien falta a su palabra «\$.

La noticia divulgada por la Iberia Musical y Literaria era lo suficientemente detallada y plausible como para que Espín hubiera abrigado esperanzas acerca del papel que el sector progresista podía tener en la transformación de lo que hasta entonces era una aspiración en una realidad. Así, siete meses después, en enero de 1844, el modesto crítico se transformaba en agitador enarbolando la bandera de la ópera nacional. Escribió entonces una especie de manifiesto en el que asumió el papel de escritor y artista con una responsabilidad política y social que se confunde con la «conservación» y «lustre» del arte lírico-dramático, planteados, por un lado, como un efecto de la protección gubernamental ${ }^{60} \mathrm{y}$, por otro, de una «necesidad de la sociedad moderna» ${ }^{61}$. Esta necesidad se relaciona con motivos políticos (las «convulsiones políticas [que] han hecho tomar nueva forma a las ideas dominantes» han contribuido a abandonar el género sacro y a «[operar] una gran revolución en la composición dramática» ${ }^{62}$ y también musicales: frente a la «brillantez» y el «entusiasmo» que inspiraban «las melodías de que tan sembradas están las óperas modernas», los conciertos instrumentales habían decaído y la música de cámara había perdido su vigencia «en los salones aristocráticos» ${ }^{63}$. La idea de que la ópera era una necesidad de la «sociedad

59 [Sin firma], "Crónica Nacional», La Iberia Musical y Literaria, 2 (9), 26-2-1843, 72. Hubo periódicos que se hicieron eco de la noticia inmediatamente después de que fuera publicada por Espín y Guillén.

60 Joaquín Espín y Guillén, «Parte musical. Del arte lírico-dramático en España», La Iberia Musical y Literaria, 3 (1), 4-1-1844, 1.

${ }^{61}$ Joaquín Espín y Guillén, "Parte musical. Del arte lírico-dramático en España (conclusión)», La Iberia Musical y Literaria, 3 (2), 11-1-1844, 9.

62 Joaquín Espín y Guillén, «Parte musical. Del arte lírico-dramático en España», La Iberia Musical y Literaria, 3 (1), 4-1-1844, 2.

63 Joaquín Espín y Guillén, «Parte musical. Del arte lírico-dramático en España (conclusión)», La Iberia Musical y Literaria, 3 (3), 11-1-1844, 9. 
moderna» es insistente en el texto y plantea la cuestión de a qué destinatarios concretos se refiere el compositor, sobre todo en un contexto que, según lamentaba la misma revista, era de decadencia con respecto al empuje filarmónico que se había vivido en la segunda mitad de la década anterior y, más específicamente, entre 1837 y $1839^{64}$, fechas coincidentes con uno de los momentos en los que los progresistas estuvieron en el poder, contemporáneo de la Constitución de 1837.

Invocando la "fe artística» como guía, Espín, en la segunda entrega de su artículo, adoptó claramente la perspectiva del «músico-compositor» que se presenta como «sacerdote fanático e inspirado por su arte» que no se ocupa del «mundo y la sociedad» como se ocupan otros artistas y que «observa [la sociedad mundana], la adivina sus secretos para presentarla en el teatro todas sus virtudes o todos sus vicios». Al mismo tiempo, sin embargo, este "filósofo", por falta de protección, se veía abocado en España a arriesgar y perder su tiempo e incluso su patrimonio con el único beneficio «de haber merecido los sufragios de sus compatriotas, y que la empresa pague los gastos». Gobierno, empresas teatrales y capitalistas deberían asumir su responsabilidad, tal como el Conservatorio Nacional «pagado por la nación» ${ }^{65}$. Espín llega al punto de identificar el «desarrollo del teatro-lírico-nacional» con el siguiente deseo: «Ansiamos vivamente que suene la hora de la nacionalidad, que no escribamos, que no se representen en nuestros teatros más producciones que las de los hijos de nuestra querida España, porque somos ante todo españoles, y preferimos lo de nuestra casa, a cuanto pueda tener de suntuoso la del vecino" ${ }^{66}$.

Es relevante que en este artículo Espín no le otorgue ningún protagonismo a la música tradicional. Para el compositor, en primer lugar, lo significativo residía en el uso de la lengua española ${ }^{67}$ : confesaba que no dejaría de la mano la cuestión de la creación de una ópera nacional hasta que no viese «cumplidos nuestros deseos de que se cante en español» ${ }^{68}$. La cursiva es del autor, que también

64 Mariano Soriano Fuertes «Abandono de la música en España», La Iberia Musical y Literaria, 3 (11), 8-2-1844, 41, así como, del mismo autor, «Estado de nuestras sociedades artísticas de Madrid», La Iberia Musical y Literaria, 3 (7), 25-1-1844, 26-7.

65 Joaquín Espín y Guillén, «Parte musical. Del arte lírico-dramático en España (conclusión)», La Iberia Musical y Literaria, 3 (3), 11-1-1844, 10.

66 Íd.

67 Recuérdese que el Diccionario nacional o Gran diccionario clásico de la lengua española, el primero que incluye en su título la expresión «lengua espańola» aplicado al castellano, editado por el progresista Ramón Joaquín Domínguez, se publicó en 1847. Véase Alvar Ezquerra (s. f.).

68 Joaquín Espín y Guillén, «De la ópera española y su importancia. Art. I», La Iberia Musical y Literaria, 3 (59), 25-7-1844, 233. 
subraya por ese medio la expresión «ópera nacional», lo cual invita a tomar en consideración la novedosa intencionalidad y las connotaciones, seguramente de carácter político, que estas expresiones tenían para el músico.

La hermandad entre poetas y compositores se concebía como una especie de profesión de fe de españolidad. De hecho, en ese mismo mes de enero, siempre en La Iberia Musical y Literaria, junto con la primera entrega del texto de Espín se publicó el artículo «Parte literaria. Consideraciones acerca del teatro español de nuestros días», firmado por José de Grijalba, y donde se lee lo siguiente: «Tal vez el drama histórico y el político sean los que están hoy llamados a disputarse los laureles de la victoria en lizas escénicas ${ }^{69}$. El primero estaba reservado en su opinión a una minoría ilustrada, puesto que se refería a «sentimientos, hábitos o hechos, casi del todo distintos de los que impulsan y conmueven a la sociedad moderna ${ }^{70}$. Concluye con el programa de prestar atención, como crítico, exclusivamente a las obras originalmente escritas en castellano. Este deseo, sin embargo, sacaba a la luz dos dificultades específicas propias de la ópera: hacerse con un buen libreto y encontrar cantantes con una formación adecuada ${ }^{71}$.

El propósito de Espín y Guillén se correspondía con un determinado programa de carácter ideológico, así formulado en una de las entregas a lo largo de las cuales se fue publicando el artículo: «Suene la hora de nacionalidad de emancipación extranjera, poblemos la escena de producciones originales, en las cuales se advierta el adelanto de ideas, el gusto, el sentimiento filosófico de la era presente, y alcanzando que sea el primer triunfo, plantemos en la escena nuestra sagrada enseńa para que tremole con gloria nuestra y admiración de los extranjeros ${ }^{72}$.

Que la música era capaz de acompañar y conformar el tiempo presente era una idea difundida igualmente en otras secciones de la revista. Por ejemplo, en junio de 1844 inició la publicación de la serie de artículos titulados «Poder social. Influencia moral de la música», cuyo original en francés era de Édouard Lenz, un autor afincado en Suiza y vinculado con la masonería ${ }^{73}$. El autor

69 José de Grijalba, «Parte literaria. Consideraciones acerca del teatro español de nuestros días», La Iberia Musical y Literaria, 3 (1), 4-1-1844, 3.

70 Íd.

71 La última entrega de la serie es la que plantea la cuestión de los cantantes. Véase Joaquín Espín y Guillén «De la ópera española y su importancia (Conclusión)», La Iberia Musical y Literaria, 3 (59), 8-8-1844, 249-50.

72 Joaquín Espín y Guillén, «De la ópera española y su importancia. Art. II», La Iberia Musical y Literaria, 3 (61), 1-8-1844, 242.

73 Se dio inicio en el número del día 9 de junio. Se trata de la traducción, realizada por José Lezán y Moreno (firma J. L. M.) de Lenz (1842). Lenz fue el coautor, juntamente 
reivindicaba una forma de entender y apreciar la música opuesta al entretenimiento. Defendía su «fuerza moral», capaz de impresionar, conmover y enternecer puesto que era «una de las formas bajo las cuales el sentimiento y el pensamiento pueden comunicarse de hombre a hombre ${ }^{74}$.

En 1846, en uno de los últimos números de la revista, entonces retornada a su título original, La Iberia Musical, Espín y Guillén retomó en una especie de editorial el tema de la relación entre la ópera y la sociedad de su época. En el artículo $^{75}$ el compositor sigue separando el campo de lo político del campo de lo artístico, aunque para hablar de este segundo, sin posicionarse en ninguna opción política concreta, utiliza un vocabulario y una retórica que están completamente moldeados según los tópicos propios del discurso progresista ${ }^{76}$. Así, la «idea del porvenir» era su aliento, tal como lo había sido de los «hombres célebres» que habían comenzado siendo «mártires» para luego alcanzar el «triunfo». Se presentaba como parte de la «juventud española», de nuevo, como uno de quienes "creyeron en el porvenir», y de nuevo como «sacerdote» de su arte. Esta juventud deseaba «romper las cadenas con las que hasta el día se la trató de sujetar férreamente», en combate contra sus «enemigos», «los adeptos a las escuelas extranjeras, [...] los admiradores de un dogma que no comprenden, [...] los esclavos viles de la moda...». En caso de perecer, les esperaba «la gloria que honra siempre las cenizas de los mártires». Añade seguidamente que «nosotros somos hijos de la revolución, vivimos en ella, y tenemos que conquistar el lugar que tenemos que ocupar», sirviéndose para ello de las organizaciones propias de la «sociedad actual»: teatros, sociedades, academias, liceos... La conclusión era una exhortación a la unidad, no de "personas», sino de "principios, de medios, de vida». Se deduce fácilmente que un llamamiento de este tipo solo se justifica cuando la situación es la contraria: o sea, a partir de este texto sería plausible incluso fechar el momento en el que la unidad de acción cuyos frutos públicos he sintetizado en el epígrafe anterior había desaparecido.

con Édouard Bobrik, de Histoire de la franc-maçonnerie: son idée fondamentale et sa constitution développées selon l'esprit de notre siècle (1841).

74 [Édouard Lenz], «Poder social. Influencia moral de la música. I.», La Iberia Musical e Ilustrada, 3 (46), 9-6-1844, 183.

75 Joaquín Espín y Guillén, «Nuestra situación», La Iberia Musical. Gaceta de teatros, 5 (15), 19-4-1846, 117-8.

76 Cabe señalar que, cuando se publicó el artículo, Espín había sido nombrado compositor de la Academia Real de Música, directamente patrocinada por la Corona. Es decir, había aceptado participar en una iniciativa del Gobierno moderado. El proyecto acabó de la peor manera, con un desfalco por el cual su principal instigador, Dionisio Scarlatti y Aldama, descendiente del célebre Domenico Scarlatti, fue denunciado ante la justicia. 


\section{PADILLA O EL ASEDIO DE MEDINA EN RED MEDIÁTICA E INTERTEXTUAL}

En 1844, Espín debió de estar bastante ocupado en la composición de la partitura de Padilla o el asedio de Medina, sobre libreto, como ya he indicado más arriba, de Romero Larrañaga. Como he adelantado en la introducción, el análisis del libreto y la partitura quedan fuera de los objetivos de este artículo ${ }^{77}$. No así su contexto teatral, que merece ser abordado manteniendo la perspectiva que nos ofrece la metáfora de la red anunciada en la introducción. El análisis cuidadoso de la recepción de esta ópera refuerza igualmente la existencia de dicha red y, por ende, la tesis principal de este artículo. Los periódicos generalistas se hicieron eco del estreno de Padilla o el asedio de Medina, aunque en su mayoría se limitaron a anunciarlo. Los medios que publicaron reseñas críticas más o menos extensas fueron La Posdata, el Semanario Pintoresco Español y la Gaceta de Madrid. Además, el diario conservador El Tiempo fue el que más piezas periodísticas dedicó al evento, un total de cinco, entre las que se incluye una crónica dentro de su revista literaria ${ }^{78}$. La posdata, según señala Eugenio Hartzenbusch en sus Apuntes para un catálogo de periódicos madrileños desde el año 1661 al 1870, «era periódico de fuerte oposición al gobierno que mandaba entonces ${ }^{79}$. El Semanario pintoresco español, fundado por Mesonero Romanos, aglutinaba a algunos escritores que, tal como Romero Larrańaga, estaban asociados con la tertulia conocida como El Parnasillo, así como con el Liceo Artístico y Literario de Madrid. Por su parte, El Tiempo, fundado días después de que Narváez constituyese su Gobierno, era el órgano de los "puritanos» ${ }^{80}$ : sabiendo que José de Salamanca, el empresario que hizo posible que se estrenase la ópera, apoyó esta tendencia del Partido Moderado, no es de extrañar el destaque que se le dio en la información publicada en este medio.

La crítica de La posdata del día 10 de julio es abiertamente elogiosa desde la primera línea, y destaca los siguientes aspectos: que los artistas y el libreto eran españoles, la forma adecuada como Romero Larrańaga se amoldó a las convenciones de la ópera y la calidad de la parte musical ${ }^{81}$.

Véase un análisis y la reproducción del libreto que escribió Larrañaga para Espín y Guillén en Cascudo (2020).

78 [Sin firma], «Revista literaria», El Tiempo, 13-7-1845, 4.

79 Hartzenbusch (1894: 74).

80 Gómez Aparicio (1967: 322).

81 [Sin firma], «Folletín. Teatro del Circo. Padilla o el asedio de Medina, drama lírico en dos actos y tres cuadros. Poesía de D. Gregorio Romero Larrañaga. Música de don [sic] Joaquín Espín y Guillén», La posdata. Periódico joco-serio, 10-7-1845, 2-3. 
«iGracias a Dios! —comienza— Tal fue la exclamación que se nos escapó involuntariamente anoche, al ver que se alzaba el telón de uno de nuestros teatros, con el objeto de presentarnos escenas líricas espańolas, cantadas en idioma español y escritas y puestas en música por españoles» ${ }^{82}$. No está firmada, por lo que incluso resulta plausible pensar que fueran los propios autores quienes se la proporcionaron al periódico. De hecho, es la única que describe muy en detalle la partitura y el libreto, citando pasajes concretos del mismo. En lo que se refiere al Semanario Pintoresco Español, los dos artículos que publicó sobre el estreno son, tal como los de $\mathrm{La}$ posdata, muy elogiosos. El segundo, firmado por Valladares y Saavedra, ya mencionado, cerraba con un soneto improvisado la misma noche del miércoles 9 de julio y dedicado a su «amigo el inspirado maestro español Joaquín Espín y Guillén». Su último terceto decía: "Al mostrarle orgulloso tu PADILLA / Dile, sin que el rubor tu frente empañe, / «iÓpera hay en España!... ¡Yo la fundo! ${ }^{83}$.

Al contrario, sí que está firmada la crónica de la Gaceta de Madrid, con las iniciales E. V. que corresponden con las del crítico musical Eduardo Vélaz de Medrano, quien, si bien no se encuadra claramente en el sector progresista, sí que había colaborado en iniciativas organizadas por Espín ${ }^{84}$. En consonancia con sus ideas y, no obstante, a pesar de su tono francamente elogioso, Velaz de Medrano lamenta que en su partitura Espín se dejara influir tanto por la escuela italiana y, de forma implícita, que no siguiera la senda de la utilización de la música tradicional ${ }^{85}$.

Además, Padilla o el asedio de Medina se puede incluir en otra red intertextual de ámbito madrileńo formada por una trilogía de temática comunera, en la que Romero Larrańaga participó como versificador y dentro de la cual se incluyen Felipe el Hermoso (1845) y Juan Bravo el Comunero (1849), cuyas situaciones dramáticas se deben a Eusebio Asquerino. Este mismo autor publicó en 1846 el drama en cuatro actos titulado Juan de Padilla. No puede haber sido accidental que en el plazo aproximado de

\section{Ibid., 2.}

83 Ramón de Valladares y Saavedra, «Parte literaria. Teatro del Circo. Función del 9 y 10 de junio. Fantasía sobre temas de Maria de Rohan, por el pianista español señor Oudrid. Padilla o el asedio de Medina, ópera nacional por el señor Espín y Guillén", Semanario Pintoresco Español, 29, 20-7-1845, 232.

84 Por ejemplo, en el tercer concierto de La Iberia Musical y Literaria, organizado en marzo de 1844.

85 E[duardo]. V[élaz]. [de Medrano]: «Crónica de teatros: Padilla o el asedio de Medina, ópera española por el Sr. Espín», Gaceta de Madrid, 3961, 19-7-1845, 3-4. 
un lustro este grupo de autores se concentrase en dramatizar el levantamiento comunero en los teatros madrileños ${ }^{86}$. Los mitos comuneros y, en general, el discurso antidespótico de defensa de la libertad se encuadran en la tradición liberal española, pero su uso ostensivo durante los primeros años del moderantismo gana un significado adicional que refuerza su adscripción, en este momento, a los sectores más avanzados, así como su función desde el punto de vista de los procesos de comunicación ${ }^{87}$. En este caso, además, para subrayar esa intención casi propagandística, el libreto de la ópera, a pesar de inspirarse en una derrota histórica, tiene un final feliz, puesto que concluye con la liberación de Medina por parte del ejército capitaneado por Padilla.

Resulta significativo señalar de forma adicional que las piezas comuneras que he mencionado más arriba fueron coetáneas, en un período muy breve, de un cambio en la recepción por parte de la audiencia, notada por Juan Eugenio Hartzenbusch en su detallada crítica a una de las representaciones de Juan de Padilla, realizada en diciembre de 1846: "[Lo que] ha palmoteado fervorosamente [...] ha sido lo que aplaude el público ahora en todos los dramas donde lo oye, sean nuevos o no: las invectivas contra los extranjeros y las alabanzas del carácter nacional, de las cuales antes hacía poco o ningún caso: recuérdese cuan desatendido pasó el espíritu patriótico en El gran capitán y en algún trozo de Un amigo en candelera» ${ }^{88}$.

Estas dos últimas piezas citadas, de la autoría del también progresista Antonio Gil y Zárate, habían sido estrenadas en 1843. Por tanto, confiando en la opinión de Hartzenbusch, se puede concluir que en poco más de tres años la percepción del público acerca de este recurso había cambiado resignificándose: la cita apunta hacia una transformación de la percepción de la audiencia, según la cual lo patriótico pasó a ser interpretado como nacional y, también, como excluyente. Además, siempre según Hartzenbusch, no solo se había convertido en un recurso manido, sino extemporáneo en piezas que estaban destinadas «solo al gusto y diversión»"

86 En 1846, Víctor Balaguer hizo lo propio en Barcelona, donde se representó su drama, homónimo al de Asquerino, Juan de Padilla.

87 Véase Romeo (2006). Agradezco a Xavier Andreu Miralles que me haya hecho notar este punto.

88 Juan Eugenio Hartzenbusch, «Crónica dramática. Estrenos», El Español, 16-121846, 3-5. Las piezas del dramaturgo también formaban parte del catálogo de la imprenta Repullés, donde estaban publicadas Felipe el Hermoso y Juan de Padilla. Su padre, tal como el de Espín, apoyó el Trienio Liberal. Íd. 


\section{CONCLUSIÓN}

Espero haber demostrado que lo que hicieron Romero Larrańaga y Espín y Guillén con la ópera Padilla o el asedio de Medina, tal como lo que hicieron quienes los acompañaron en diversas iniciativas artísticas de carácter literario y musical o empresarial, rozó, y mucho, la política. La mencionada ópera formó parte de una red de carácter social, mediático e intertextual que se tejió durante los meses en los que sus autores, todos ellos situados en la órbita del progresismo, asistieron al fin de la Regencia de Espartero y al comienzo de la Década Moderada. Ante la exigencia de responder a estas circunstancias aunaron sus esfuerzos, concretados en obras artísticas y acciones cuya interpretación estuvo directamente condicionada por el presente. Su consistente activismo artístico y cultural tuvo una dimensión sonora que este artículo, por primera vez, ha puesto en evidencia y que en futuros trabajos relativos a la historia de los intelectuales y también de la literatura y del teatro declamado y musical en España debería ser tomada en consideración. Por un lado, se manifestó en una línea más popular (ilustrada en la música que Espín y Guillén escribió para la canción "Las rosas de amor», sobre texto de Ayguals de Izco, incluida en María, la hija de un jornalero). Por otro lado, tuvo una faceta más minoritaria, la del teatro histórico y político, ilustrada a su vez por el libreto de Padilla o el asedio de Medina. Todavía la ejecución, audición y apreciación de obras musicales, vocales e instrumentales, tuvo un papel relevante en los entornos de sociabilidad que frecuentaron, puesto que juntamente con la recitación de poesía constituían uno de los objetivos de muchas de sus reuniones. De forma adicional, La Iberia Musical y sus sucesivas series, convertida en La Iberia Musical y Literaria, ilustra bien hasta qué punto la música formó igualmente parte del modelo de negocio que estos autores crearon como respuesta a las necesidades de la sociedad moderna contemporánea. Este activismo no se correspondió con una militancia monolítica: todos ellos participaron en un movimiento de oposición ocupando posiciones políticas con diferente grado de radicalidad, que iban desde el centrismo hasta el republicanismo.

Después de lo expuesto, no resulta plausible pensar que, dado su mensaje político, la ópera de Romero Larrañaga y Espín y Guillén hubiera podido sobrevivir al consenso alcanzado durante la Década Moderada, que se prolongó entre mayo de 1844 — cuando la obra estaba en un estado avanzado, sino es que no había sido concluida ya-y julio de 1854, poco antes del nombramiento sin sueldo de Espín y Guillén como organista de la Capilla Real y de que la reina Isabel II le distinguiera con la orden de Carlos III. En 1850 se abrió el Teatro Real y en 1851 inició su andadura — precisamente en 
el mismo escenario del Teatro Circo donde se había estrenado en 1845 Padilla o el asedio de Medina - la Sociedad Artístico-Musical que en 1856 inauguró el Teatro de la Zarzuela. Espín y Guillén quedó relegado a un segundo plano en el campo de la música: no formó parte de la Sociedad Artístico-Musical y su compromiso con el Teatro Real se limitó a las funciones de maestro del coro. Es decir, además de que el texto y el subtexto de su ópera ya no venían al caso en la nueva situación política, él mismo quedó excluido de los lugares desde los cuales se gestó el curso del teatro lírico en Madrid. Al margen cabe señalar que todavía queda mucho por hacer en el sentido de analizar la producción de compositores españoles del entorno del Teatro de la Zarzuela, así como los motivos de su exclusión casi total del cosmopolita escenario del Teatro Real y el predominio de los espectáculos líricos de entretenimiento y de apariencia apolítica tomando como referencia de lectura las coordenadas ideológicas y políticas del discurso hegemónico moderado en estos años.

Espero haber mostrado además que la aportación de Romero Larrañaga y Espín y Guillén a la creación de una ópera nacional o española solo es inteligible si se encuadra dentro de una cultura política concreta; en este caso la del liberalismo progresista, consolidada y actualizada a través de redes de sociabilidad en las que la música tuvo un papel relevante. La ópera nacional fue en el siglo XIX, ante todo, un proyecto que debe ser analizado en consonancia con el carácter contingente propio del proyecto más amplio del que forma parte, el de nacionalización, el cual es a su vez inseparable de la disputa entre diferentes facciones políticas. Esto, que puede parecer una afirmación superflua, en lo que respecta al caso de la ópera española decimonónica nunca había sido señalado de forma tan explícita. En lo concerniente a Padilla o el asedio de Medina en particular, no solo el tópico de los comuneros, sino también el uso del español y del modelo transnacional de la ópera en italiano, así como la renuncia a prestar atención al elemento popular de manera localista, territorial o clasista son elementos que refuerzan esta idea. El objetivo que tenían sus autores era representar la nación bajo una serie de condiciones, en consonancia con cierta idea de progreso o adelanto de ideas y a través de la difusión de los símbolos apropiados.

\section{Bibliografía}

Alvar Ezquerra, M. (s. f.). Domínguez, Ramón Joaquín (1811-1848). En M. Alvar Ezquerra (ed.). Biblioteca Virtual de la Filología Española (BVFE). Disponible en: https://bit. ly/3a2WLCe.

Álvarez Junco, J. (2001). Mater Dolorosa. La idea de España en el siglo XIX. Madrid: Taurus. 
Andreu Miralles, X. (2017). Articular la nación la María de Ayguals de Izco y la nacionalización española (1845-1850). Rubrica Contemporánea, 6 (11), 25-43. Disponible en: https://doi.org/10.5565/rev/rubrica.135.

- (2019). Naufragio operístico y lauro zarzuelero. Lo transnacional y la dispar suerte de los «aires españoles». En X. Andreu Miralles (ed.). Vivir la nación: nuevos debates sobre el nacionalismo español (pp. 55-80). Granada: Editorial Comares.

Baulo, S. (2005). Prensa y publicidad en el siglo xix: el caso de la Sociedad Literaria de Madrid (1845-1846). En J. M. Desvois (ed.). Prensa, impresos, lectura en el mundo hispánico contemporáneo: homenaje a Jean-François Botrel (pp. 61-71). Burdeos: Université Michel de Montaigne Bordeaux 3/PILAR.

Burdiel, I. (2000). La tradición política progresista. Historia de un desencuentro. En C. Dardé Morales (ed.). Sagasta y el liberalismo español (pp. 103-121). Madrid: Fundación BBVA.

Carreras, J. J. (2018). Historia de la música en España. Siglo XIX. Madrid: Fondo de Cultura Económica.

Casares Rodicio, E. (1998). La música española en el siglo XIX. Oviedo: Universidad de Oviedo.

— (2017). El libreto en la construcción de la ópera nacional. En M. del P. Espín Templado, P. de Vega Martínez y M. Lagos (eds). Teatro lírico español: ópera, drama lírico y zarzuela grande entre 1868 y 1925 (pp. 13-56). Madrid: Universidad Nacional de Educación a Distancia.

(2019). La ópera en España. Procesos de recepción y modelos de creación. II. Desde la Regencia de María Cristina hasta la Restauración alfonsina (1833-1874). Madrid: Instituto Complutense de Ciencias Musicales.

Cascudo, T. (2020). Un libreto inédito para una ópera española y progresista: Padilla o el asedio de Medina (1845), de Gregorio Romero de Larrańaga. Berceo, 178, 183-220.

Díez Huerga, M. A. (2004). Las sociedades musicales en el Madrid de Isabel II (1833-1868). Anuario Musical, 58, 253-277. Disponible en: https://doi.org/10.3989/anuariomusical.2003.58.76.

Fuentes Garzón, S. (2018). El periódico de Joaquín Espín y Guillén: La Iberia Musical (Madrid, 1842). En H. Lima, A. I. Reis, P. Costa (eds.). Comunicación y Espectáculo: Actas del XV Congreso de la Asociación de Historiadores de la Comunicación (pp. 392-407). Porto: Universidade do Porto.

Fulcher, J. (1987). The Nation's Image: French Grand Opera as Politics and Politicized Art. Cambridge: Cambridge University Press.

Gómez Aparicio, P. (1967). Historia del periodismo español: desde la "Gaceta de Madrid», 1661, hasta el destronamiento de Isabel II. Madrid: Editora Nacional.

Guardia Herrero, C. de la. (2014). Las culturas de la sociabilidad y la transformación de lo político. En M. C. Romeo y M. Sierra (eds.). La España Liberal, 1833-1874 (pp. 189-215). Madrid; Zaragoza: Marcial Pons; Prensas de la Universidad de Zaragoza.

Gutiérrez, C. J. (2010). La lección de guitarra de Miguel Agustín Príncipe. Roseta. Revista de la Sociedad Española de Guitarra, 63, 62-81.

Hartzenbusch, E. (1894). Apuntes para un catálogo de periódicos madrileños desde el año 1661 al 1870. Madrid: Tipografía Sucesores de Rivadeneyra. 
Hidalgo, D. (1844). Boletín bibliográfico español y extranjero, Tomo IV. Correspondiente al año de 1843. Madrid: Imprenta de Hidalgo.

Lenz, É. (1842). Idées sur le pouvoir social et l'influence morale de la musique: exposées à l'Académie de Lausanne. Lausanne: M. Ducloux.

Lenz, É. y Bobrik, É. (1841). Histoire de la franc-maçonnerie: son idée fondamentale et sa constitution développées selon l'esprit de notre siècle. Lausanne: M. Ducloux.

Locke, R. P. (1986). Music, Musicians, and the Saint-Simonians. Chicago: Chicago University Press.

Martínez Martín, J. (2018). Los negocios y las letras: el editor Francisco de Paula Mellado (18071876). Zaragoza: Prensas de la Universidad de Zaragoza.

Martínez Villergas, J. (1854). Juicio crítico de los poetas españoles contemporáneos. París: Librería de Rosa y Bouret.

Mellado y Orejuela, F. de P. (1850). Diccionario Universal de Historia y Geografía, Tomo VIII, Suplemento. Madrid: Establecimiento Tipográfico de Francisco de Paula Mellado.

Millán, J. y Romero, M. C. (2008). ¿Por qué es importante la revolución liberal en España? Culturas políticas y ciudadanía en la historia española. En M. Bruguera y C. Schmidt-Novara (eds.). Historia de España contemporánea. Cambio social y giro cultural (pp. 17-43). Valencia: Prensas de la Universidad de Valencia.

Natali, F. (2009). Pasquale Cataldi, poeta improvvisatore gallipolino (1807-1867). Tuglie: Tipografia 5 Emme.

Pasler, J. (2009). Composing the Citizen: Music as Public Utility in Third Republic France. Berkeley: University of California Press. Disponible en: https://doi.org/10.1525/ 9780520943872.

Pérez Núńez, J. (2016). Conmemorar la nación desde abajo. Las celebraciones patrióticas del Madrid progresista, 1836-1840. Historia y Politica, 35, 177-202. Disponible en: https:// doi.org/10.18042/hp.35.08.

Pérez Roldán, C. (1999). La prensa republicana madrileña durante el siglo xıx: «La Igualdad» $\mathrm{y}$ «El Combate» como ejemplos de periódicos republicanos. Historia y Comunicación Social, 4, 317-340.

Peyrou, F. (2008). Tribunos del pueblo. Demócratas y republicanos durante el reinado de Isabel II. Madrid: Centro de Estudios Políticos y Constitucionales.

Prieto Benavent, J. L. (2000). Los puritanos: orígenes del centrismo político en la España del siglo $X I X$ [tesis doctoral]. Universidad Nacional de Educación a Distancia.

Queipo, C. (2015). Elite, coleccionismo y prácticas musicales en La Coruña de La Restauración (ca. 1815-1848): el fondo musical Adalid [tesis doctoral]. Universidad de La Rioja. (2019a). Redes, élites y sociedades filarmónicas en el Trienio Liberal (1820-1823): los casos de A Coruña y Madrid a través de la prensa. En C. Queipo y M. Palacios (eds.). El asociacionismo musical en España: estudios de caso a través de la prensa (pp. 187-224). Logroño: Calanda Ediciones Musicales.

(2019b). Prácticas musicales y procesos de civilización de la élite financiera y comercial en la España de Femando VII: el caso de A Coruña. En J. M. Imízcoz Beunza, M. García Fernández y J. E. Ochoa de Eribe (eds.). Procesos de civilización: culturas de élites, culturas populares: una historia de contrastes y tensiones (siglos XVI-XIX) (pp. 191-212). Bilbao: Universidad del País Vasco/Euskal Herriko Unibertsitatea. 
Rodríguez Lozano, G. A. (2006). Joaquín Espín y Guillén (1812-1882): una vida en torno a la ópera española. Cuadernos de Música Iberoamericana, 12, 63-38.

Romeo, M. C. (2003). Los mundos posibles del liberalismo progresista. En G. Ramírez Aledón y E. La Parra López (eds.). El primer liberalismo: España y Europa, una perspectiva comparada: foro de debate, Valencia, 25 a 27 de octubre de 2001 (pp. 287-314). Valencia: Biblioteca Valenciana.

(2006). La tradición progresista: historia revolucionaria, historia nacional. En M. Suárez Cortina (ed.). La redención del pueblo (pp. 81-114). Santander: Universidad de Cantabria.

Scardicchio, A. (2012). Declamazione per la nazione. La parabola degli improvvisatori in Salento i la questione unitaria. Amaltea Trimestrale di Cultura, 7 (4), 33-49.

Sierra, M. (2010). La cultura política en el estudio del liberalismo y sus conceptos de representación. En M. Pérez Ledesma y M. Sierra (eds.). Culturas políticas: teoría e historia (pp. 233-261). Zaragoza: Institución Fernando el Católico; Consejo Superior de Investigaciones Científicas.

Simón Montiel, A. (2015). Liszt en la Península Ibérica. Su discurso musical y su reflejo en los medios [tesis doctoral]. Universidad de Málaga. Disponible en: https://bit.ly/3A2TBt3.

Sorba, C. (2011). Ernani Hats: Italian Opera as a Repertoire of Political Symbols during the Risorgimento. En J. Fulcher (ed.). The Oxford Handbook of the New Cultural History (pp. 428-452). Oxford: Oxford University Press. Disponible en: https://doi. org/10.1093/oxfordhb/9780195341867.013.0018.

- (2015). Il melodramma della nazione. Politica e sentimenti nell'età del Risorgimento. Roma; Bari: Laterza.

Vilches, J. (2001). Progreso y libertad. El partido progresista en la revolución liberal española. Madrid: Alianza Ensayo.

Villarroya, J. T. (1977). Las elecciones de 1844. Revista de Estudios Politicos, 211, 61-122. 